\title{
Characterization of amorphous hydrogenated chlorinated plasma polymers
}

\author{
Diego Rossi ${ }^{\mathrm{a}, 1}$, Wido H. Schreiner ${ }^{\mathrm{b}}$, Steven F. Durrant ${ }^{\mathrm{a}, *}$ \\ a Laboratório de Plasmas Tecnológicos, Instituto de Ciência e Tecnologia de Sorocaba, UNESP, Sorocaba, SP, Brazil \\ b Departamento de Física, Universidade Federal de Paraná, Curitiba, PR, Brazil
}

\section{A R T I C L E I N F O}

\section{Article history:}

Received 13 October 2015

Revised 25 January 2016

Accepted in revised form 28 January 2016

Available online 29 January 2016

\section{Keywords:}

PECVD

Chlorinated films

Plasma polymers

Tauc gap

\begin{abstract}
A B S T R A C T
Thin films were produced by plasma enhanced chemical vapor deposition from propanol-chloroform-argon mixtures. The main system parameter studied was the percentage of chloroform in the chamber feed, $\mathrm{C}_{\mathrm{Cl}}$. Plasma polymers doped with chlorine were produced at deposition rates of up to $110 \mathrm{~nm} \mathrm{~min}^{-1}$. As revealed by infraredand X-ray photoelectron spectroscopy, the films consisted of a hydrogenated carbon matrix with a carbon content of at least 80 at.\%, and a roughly constant oxygen content of about 12 at.\%. A maximum chlorine content of $\sim 8$ at.\% was obtained. The surface contact angle of the films was around $75^{\circ}$, and was reduced slightly at greater chlorine contents. Optical properties were obtained from ultraviolet-visible-near infrared spectroscopic data. While the refractive index of the films was around 1.56 independently of $\mathrm{C}_{\mathrm{Cl}}$, the chlorinated films showed a distinct optical gap of $\sim 2.5 \mathrm{eV}$ compared to $\sim 1.9 \mathrm{eV}$ for the unchlorinated film.
\end{abstract}

(c) 2016 Elsevier B.V. All rights reserved.

\section{Introduction}

Plasmas containing chlorine or chlorine-containing species have long been used to alter the properties of surfaces. Inagaki et al. [1,2], for example, used $\mathrm{CCl}_{4}$ plasmas to introduce chlorine (and oxygen) onto the surfaces of conventional polymers, thus, for example, decreasing the surface contact angle of polypropylene [1]. Similarly, the same group also reported the chlorination of polypropylene in chloroform plasmas, thereby reducing the contact angle from $95^{\circ}$ to $73^{\circ}$ [2]. Roughly a decade later, Upadhyay and Bhat reported the treatment of polypropylene in chloroform, carbon tetrachloride or dichloromethane plasmas [3]. Tyczkowski et al. [4] improved the peel-strength of rubber surfaces by treating them in $\mathrm{CCl}_{4}, \mathrm{Cl}_{2}$ or $\mathrm{CHCl}_{3}$ plasmas. More recently, Lu et al. [5] used a plasma fixed-bed reactor to chlorinate Poly(Vinyl) Chloride (PVC) particles to 67 at.\%. Chlorine-plasma treatment of organic lightemitting diodes is known to improve the efficiency and reliability of these devices [6].

Over the last few years, atmospheric pressure plasmas have begun to be studied for the deposition of chlorinated films [7,8]. Atmospheric plasmas fed with $\mathrm{C}_{4} \mathrm{Cl}_{6}$ or $\mathrm{C}_{2} \mathrm{H}_{2} \mathrm{Cl}_{4}$ can produce stable chlorinated films [7]. Both $\mathrm{C}-\mathrm{Cl}$ and $\mathrm{C}-\mathrm{Cl}_{2}$ functionalities can be detected in the films by $\mathrm{X}$-ray photoelectron spectroscopy (XPS). Chlorinated thin films have also been deposited onto zinc-plated steel wires from dichloromethane plasmas [8].

\footnotetext{
* Corresponding author.

E-mail address: steve@sorocaba.unesp.br (S.F. Durrant).

1 POSMAT student.
}

Despite being a well-established technique, cold, low pressure plasma deposition for the production of chlorinated thin films has received relatively little attention. Chlorinated silicon dioxide films have been produced by remote plasma enhanced chemical vapor deposition (PECVD) of $\mathrm{SiCl}_{4}, \mathrm{O}_{2}$, Ar and $\mathrm{H}_{2}$, but the material produced under optimized conditions is close in stoichiometry to that of $\mathrm{SiO}_{2}$. To retain dense material resistant to water absorption the chlorine content should not exceed 2.6 at.\% [9]. Chlorine in doped silicon dioxide films can passivate sodium ion impurities and neutralize dangling bonds in gate dielectrics for use in ULSI (Ultra Large Scale Integrated) circuits (Ref. [9] and references therein). Thus in such applications the emphasis is on retaining desired electronic or optoelectronic properties while improving film stability rather than on obtaining chlorinated films. Similarly, Arai et al. [10] produced a-Si:H(Cl) and $\mu c-\mathrm{Si}: \mathrm{H}(\mathrm{Cl})$ films from mixtures of dichlorosilane, silane and hydrogen by PECVD. The resulting films showed high photoconductivity, $\sim 10^{-6}$ to $10^{-5} \mathrm{~S} \mathrm{~cm}^{-1}$, under an illumination of $100 \mathrm{~mW} \mathrm{~cm}^{-2}$. Increases in electrical conductivity of about five orders of magnitude to the $10^{-5}$ to $10^{-3} \mathrm{~S} \mathrm{~cm}^{-1}$ range were obtained by the PECVD of pyrrole or thiophene with chloroform [11]. Again, the films were not highly chlorinated, having a maximum chlorine content of $\sim 4$ at.\%.

Chlorine-containing plasma polymers potentially have diverse applications. For example, plasma polymerized trichloroethene coatings with $\mathrm{Cl}$ contents of up to 43.2 at.\% show strong antimicrobial properties, specifically against Staphylococcus epidermidis [12]. The dyeability of cotton and polyester can be improved by treatment in dichloromethane plasmas [13].

Cold plasma deposition from chloroform-acetylene-argon mixtures has also been demonstrated [14]. As revealed by XPS analyses, chlorine contents of up to 47.5 at.\% can be obtained. The Tauc optical gap of the 
deposited material could be controlled in the 1.7 to $2.8 \mathrm{eV}$ range, depending on the proportion of chloroform in the reactor feed. An even higher Tauc gap, of $2.97 \mathrm{eV}$, was reported for a film produced by plasma immersion ion implantation and deposition (PIIID) of an acetylene-chloroform mixture [15]. Chlorine contents as high as 62.4 at.\% can be reached [16].

In the present work films were produced from cold plasmas fed mixtures of propanol, chloroform and argon $\left(\mathrm{CH}_{3}\left(\mathrm{CH}_{2}\right)_{2} \mathrm{OH}, \mathrm{CHCl}_{3}\right.$, and $\left.\mathrm{Ar}\right)$. The key parameter was the proportion of chloroform in the feed, $\mathrm{C}_{\mathrm{Cl}}$. Deposition rates and surface contact angles were measured; infrared- and $\mathrm{X}$-ray photoelectron spectroscopic analyses were made. From transmission ultraviolet-visible spectra and film thickness data, refractive indices, absorption coefficients and optical gaps were calculated.

\section{Experimental}

Films were produced by PECVD in a conventional in-house built radiofrequency system described in detail elsewhere [17]. In brief, a cylindrical stainless-steel chamber is fed gases via precision flowmeters and vapors of liquid monomers from glass vessels sealed by needle valves. The chamber holds horizontal parallel-plate electrodes, of $100 \mathrm{~mm}$ diameter, set $50 \mathrm{~mm}$ apart. While radiofrequency power (forward applied power $70 \mathrm{~W}, 13.56 \mathrm{MHz}$, Tokyo Hy-power RF-150 supply), was fed to the lower electrode via a matching network (Tokyo Hy-power MB300), the upper electrode was earthed. A base pressure of about $1 \mathrm{mPa}$ could be reached prior to deposition using an Edwards diffusion pump. During depositions the system was evacuated continuously by a rotary-vane pump (Edwards, E2M18).

Propanol and chloroform vapors were fed to the chamber via glass vials containing the liquid monomers, and closed by needle valves (Edwards, LV10K). Argon was introduced via precision mass flow controllers (MKS, maximum range $10 \mathrm{sccm}$ ). For the depositions, a total pressure of 53.4 Pa and a fixed propanol pressure of 26.7 Pa established in the absence of the discharge were used. The partial pressure of chloroform in the feed, $\mathrm{C}_{\mathrm{Cl}}$, was varied from 0 to $40 \%$, while the pressure of argon was correspondingly decreased.

Substrates of dimensions ( $\mathrm{mm}$ ) of $10 \times 20 \times 2$ were placed on the lower electrode. The choice of the substrate depends on the subsequent proposed analysis. Glass, polished stainless-steel, aluminum and quartz were used, respectively, for analyses by Profilometry and Goniometry, Infrared reflection-absorption spectroscopy (IRRAS), X-ray photoelectron spectroscopy (XPS), and Transmission ultraviolet visible spectroscopy (UVS).

Film thickness, d, was measured by profilometry of a film step-height prepared by film deposition on a partially-covered glass slide. Nine horizontal scans of $2000 \mu \mathrm{m}$ obtained using a Veeco Dektak 150 profilometer were taken. From the deposition time, $t$, the deposition rate, $\mathrm{R}$, was obtained by employing the relation $\mathrm{R}=\mathrm{d} / \mathrm{t}$. Using a Ramé-hart 100-00 goniometer, surface contact angles were measured on drops of distilled deionized water placed on the film surface. Thirty measurements per film were taken. A Jasco FT/IR-410 was used for Infrared reflectionabsorption spectroscopy in the 4000 to $600 \mathrm{~cm}^{-1}$ range. A resolution of $4 \mathrm{~cm}^{-1}$ was achieved; 128 scans per spectrum were accumulated. For the XPS analyses a VG Microtech-ESCA 3000 spectrometer, which employs a beam of $\mathrm{MgK}_{\alpha}$ radiation $(1253.6 \mathrm{eV})$ at an incidence angle of $45^{\circ}$, was used. Sample surfaces were analyzed without sputter cleaning. The resolution was about $0.8 \mathrm{eV}$. Ultraviolet-visible-near infrared spectroscopy (UVS) was carried out suing a Perkin-Elmer 1050 instrument to obtain transmittance spectra in the wavelength range from 190 to $3300 \mathrm{~nm}$. The resolution was $0.2 \mathrm{~nm}$ or better over this range.

\section{Results and discussions}

\subsection{Deposition rate and roughness}

Fig. 1a shows the deposition rate, $\mathrm{R}$, as a function of $\mathrm{C}_{\mathrm{Cl}}$. As can be observed from the figure, $R$ increases with from $\sim 10$ to $\sim 110 \mathrm{~nm} \mathrm{~min}^{-1}$ as

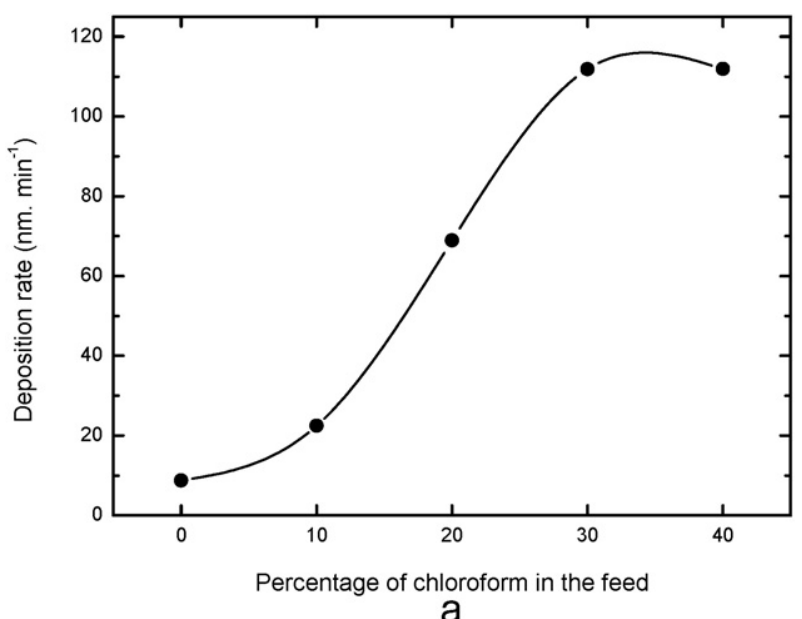

a

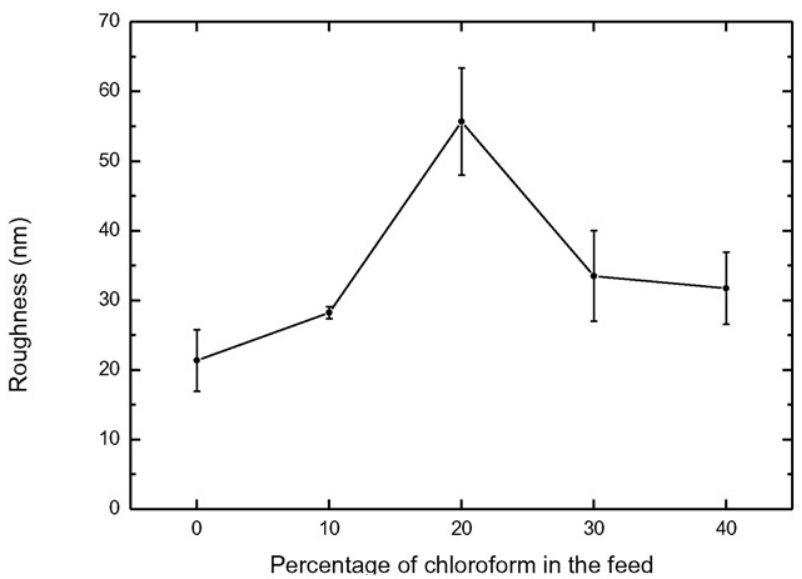

b

Fig. 1. a. Deposition rate as a function of the percentage of chloroform in the feed, $C_{C 1}$. The film thicknesses (in $\mathrm{nm}$ ) for depositions at increasing values of $\mathrm{C}_{\mathrm{Cl}}$ (from 0 to $40 \%$ ) were, respectively, 524, 786, 1241, 1678 and 1679 . b. Film surface roughness $\left(R_{a}\right)$ as a function of $\mathrm{C}_{\mathrm{Cl}}$.

$\mathrm{C}_{\mathrm{Cl}}$ is increased from zero to $40 \%$. Thus plasmas fed propanol (and argon) form films at a relatively low rate, presumably from $\mathrm{CH}_{\mathrm{x}}$ precursors. It is also known that $\mathrm{CHCl}_{3}$ or $\mathrm{CHCl}_{3}-\mathrm{Ar}$ plasmas do not deposit films. The marked rise in $\mathrm{R}$ (by more than an order of magnitude) as $\mathrm{C}_{\mathrm{Cl}}$ increases is therefore noteworthy.

Owing to the bond strengths of $\mathrm{C}-\mathrm{H}$ and $\mathrm{C}-\mathrm{Cl}$, of $4.4 \mathrm{eV}$ and $3.5 \mathrm{eV}$, respectively [7], the latter are more readily broken. Chlorine may be lost as $\mathrm{HCl}$, which is consistent with the small incorporation of chlorine determined by IRRAS and XPS, to be discussed later.

To our knowledge the electron density and electron energy distribution function have not been studied in cold plasmas of propanol or chloroform. In high power pulsed RF plasmas (300 ms at $400 \mathrm{~W}$ ) of $\mathrm{CHCl}_{3}$ highly diluted in $\mathrm{H}_{2}$, however, chlorine-containing species are known to be practically eliminated and, in a few milliseconds, converted to such species as $\mathrm{HCl}, \mathrm{CH}_{4}$ and $\mathrm{C}_{2} \mathrm{H}_{2}$ which are then converted to the radicals $\mathrm{CH}_{3}, \mathrm{Cl}$ and $\mathrm{H}$ [18]. Despite the differences in the initial plasma composition and applied power used compared to those employed in the present study, we speculate that the net result is similar, producing $\mathrm{CH}_{\mathrm{x}}, \mathrm{Cl}$ and $\mathrm{H}$. The $\mathrm{CH}_{\mathrm{x}}$ radicals are probably the film precursors, while $\mathrm{Cl}$ and $\mathrm{H}$ are lost relative to their values in the chamber feed.

A little $\mathrm{Cl}$ is retained in the growing films but $\mathrm{Cl}$ also causes etching, which may explain the stability of the deposition rate as $\mathrm{C}_{\mathrm{Cl}}$ is increased beyond $30 \%$. Film surface roughness, $R_{a}$, calculated from film profiles, is shown in Fig. 1b. The observed increase in roughness at greater $\mathrm{C}_{\mathrm{Cl}}$ is consistent with greater etching. 


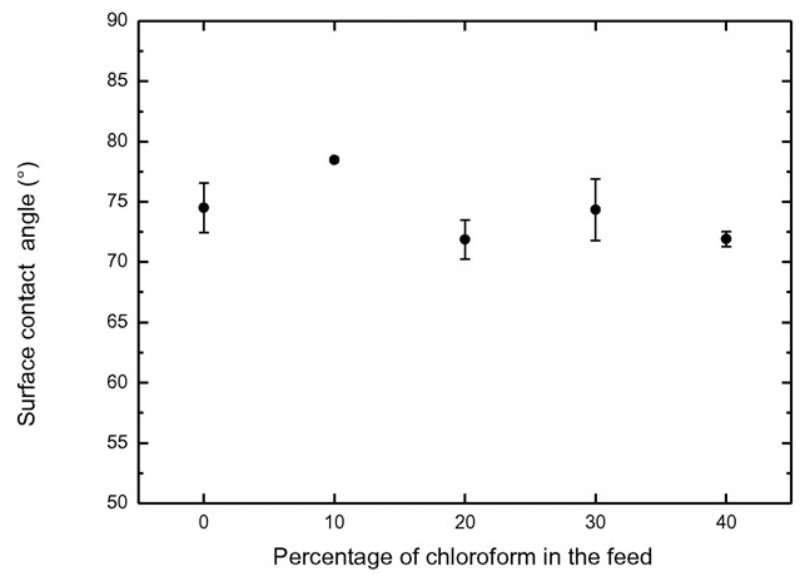

Fig. 2. Surface contact angle as a function of the percentage of chloroform in the feed, $\mathrm{C}_{\mathrm{Cl}}$.

\subsection{Surface contact angle measurements}

Fig. 2 shows the surface water contact angle, $\theta$ as a function of $\mathrm{C}_{\mathrm{Cl}}$. Irrespective of $\mathrm{C}_{\mathrm{Cl}}$, the surface contact angle is always around $75^{\circ}$. Thus the structural and compositional modifications observed in the films are insufficient to significantly modify $\theta$. The value of $75^{\circ}$ is consistent with that of conventionally conjugated PVC of $\sim 74^{\circ}$ [19], and somewhat above that of conventional polyethylene $\sim 66^{\circ}$ [20]. There is a slight tendency, however, for the contact angle to be reduced by a few degrees by chlorination. This is consistent with trends observed, for example, in the surface chlorination of styrene-butadiene rubber ( $\mathrm{F} 435)$ in $\mathrm{CHCl}_{3}$ plasmas at $80 \mathrm{~W}[4]$.

\subsection{Infrared spectroscopic analyses}

Fig. 3 shows the transmission infrared spectra of the films, deposited onto polished stainless-steel substrates, over the 400 to $4000 \mathrm{~cm}^{-1}$ range. All the spectra exhibit absorption peaks at 2950, 2900 and $2850 \mathrm{~cm}^{-1}$ caused by $\mathrm{CH}, \mathrm{CH}_{2}$ and $\mathrm{CH}_{3}$ groups, respectively. Owing to absorptions by $\mathrm{CH}_{2}$ and $\mathrm{CH}_{3}$ groups, respectively, all the spectra show bands at 1450 and $1380 \mathrm{~cm}^{-1}$.

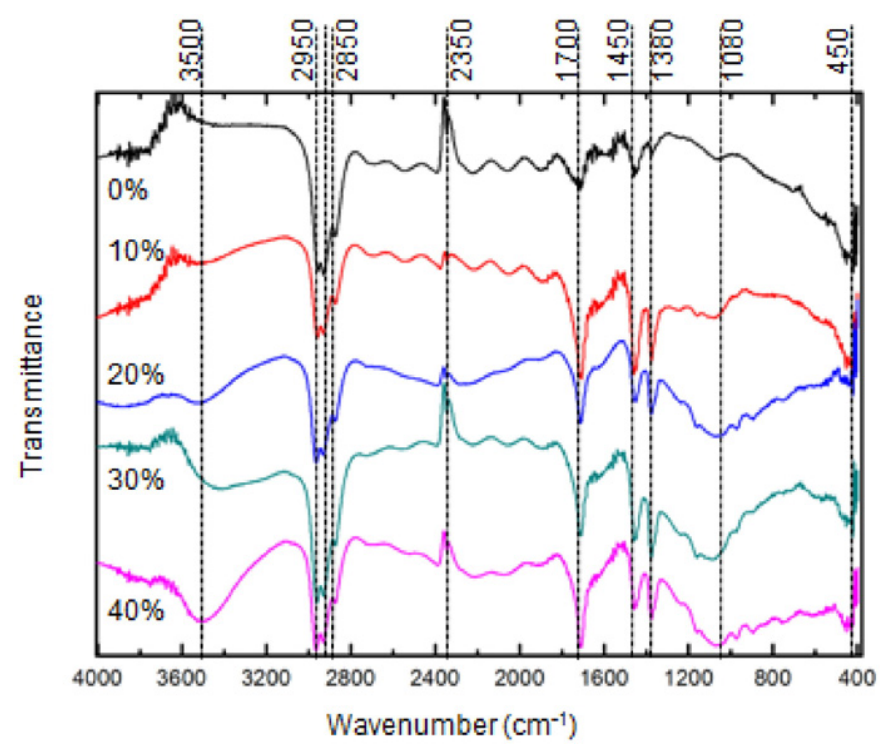

Fig. 3. Transmittance infrared spectra of films deposited at different values of $\mathrm{C}_{\mathrm{Cl}}$.
At low $\mathrm{C}_{\mathrm{Cl}}$ the absorption at $\sim 3500 \mathrm{~cm}^{-1}$ attributed to $\mathrm{OH}$ is absent or weak but is prominent at a $\mathrm{C}_{\mathrm{Cl}}$ of $40 \%$. An absorption at $1700 \mathrm{~cm}^{-1}$ is also detected in all the spectra, and is attributed to the presence of $\mathrm{C}=\mathrm{O}$ structures.

No absorptions attributable to $\mathrm{C}-\mathrm{Cl}$ stretching absorptions were detected at $\sim 770 \mathrm{~cm}^{-1}$, which may simply reflect the low $\mathrm{Cl}$ content even for the most chlorinated film ( $~ 8$ at.\% as measured by XPS, and described below).

Fig. 4 shows the relative concentrations of the species $\mathrm{CH}$ (in $\mathrm{CH}_{3}$ groups) and $\mathrm{C}=\mathrm{O}$ in the films as a function of $\mathrm{C}_{\mathrm{Cl}}$. These tendencies were obtained using the method described by Lanford and Rand [21] using the absorption bands at $1380 \mathrm{~cm}^{-1}$ and $1700 \mathrm{~cm}^{-1}$, respectively. The chlorinated films show greater concentrations of $\mathrm{CH}$ in $\mathrm{CH}_{3}$ groups than the film deposited without chloroform in the feed. A subsequent trend to lower $[\mathrm{CH}]$ in $\mathrm{CH}_{3}$ groups, however, is observed in the decline in the curve for $\mathrm{CH}$ beyond an $\mathrm{R}_{\mathrm{Cl}}$ of $\sim 10 \%$.

Although the oxygen content of the films is roughly constant (as revealed by XPS analyses to be presented later), the density of $\mathrm{C}=0$ groups also tends to decrease for $\mathrm{C}_{\mathrm{Cl}}>10 \%$. Infrared absorptions caused by $\mathrm{OH}$ are only clearly visible for $\mathrm{C}_{\mathrm{Cl}} \geq 20 \%$, however (Fig. 3), indicating that in these conditions oxygen is bound as $\mathrm{OH}$ rather than $\mathrm{C}=0$.

\subsection{X-ray photoelectron spectroscopic analyses}

Fig. 5 shows the concentrations (at.\%) of chlorine, oxygen and carbon determined in the films using XPS. The hydrogen content has been ignored since it cannot be quantified using this technique.

An increase in $[\mathrm{Cl}]$ is observed as $\mathrm{C}_{\mathrm{Cl}}$ is increased but the maximum concentration is only $\sim 8$ at.\%. This result is consistent with the absence of $\mathrm{C}-\mathrm{Cl}_{\mathrm{x}}$ absorptions in the IRRAS spectra.

The oxygen content of the films is roughly constant at $~ 12$ at.\%. Oxygen is present in the propanol molecule, and is also known to arise from post-deposition reaction of free-radicals trapped in the film and ambient oxygen and water vapor [22-23]. The films, however, are oxygen-poor considering that the oxygen content predicted from the stoichiometry of the propanol is 25 at.\% for the film deposited without chloroform in the feed. As $\mathrm{C}_{\mathrm{Cl}}$ is increased from 0 to $40 \%$, the carbon content decreases from $\sim 88$ at.\% to $\sim 80$ at.\%, while the chlorine content increases from 0 to $\sim 8$ at.\%.

The $\mathrm{C} 1 \mathrm{~s}$ peak is sensible to the local atomic environment of the $\mathrm{C}$ atoms but the low $\mathrm{Cl}$ content and the relatively high $\mathrm{O}$ content of the films impedes useful information being extracted by deconvolution of this peak.

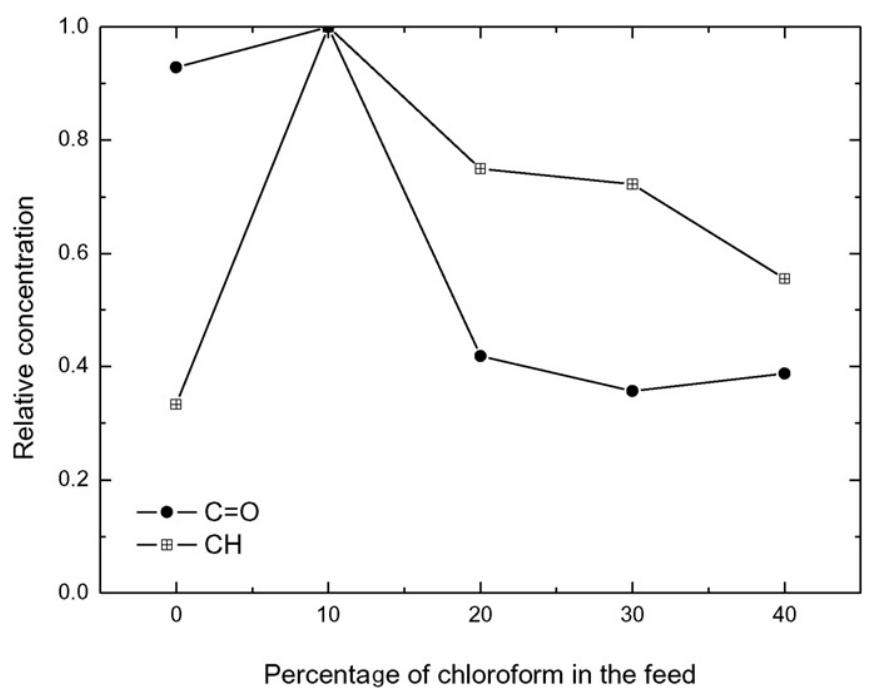

Fig. 4. Relative concentration of $\mathrm{CH}$ and $\mathrm{C}=\mathrm{O}$ bonds as a function of the percentage of chloroform in the feed. 


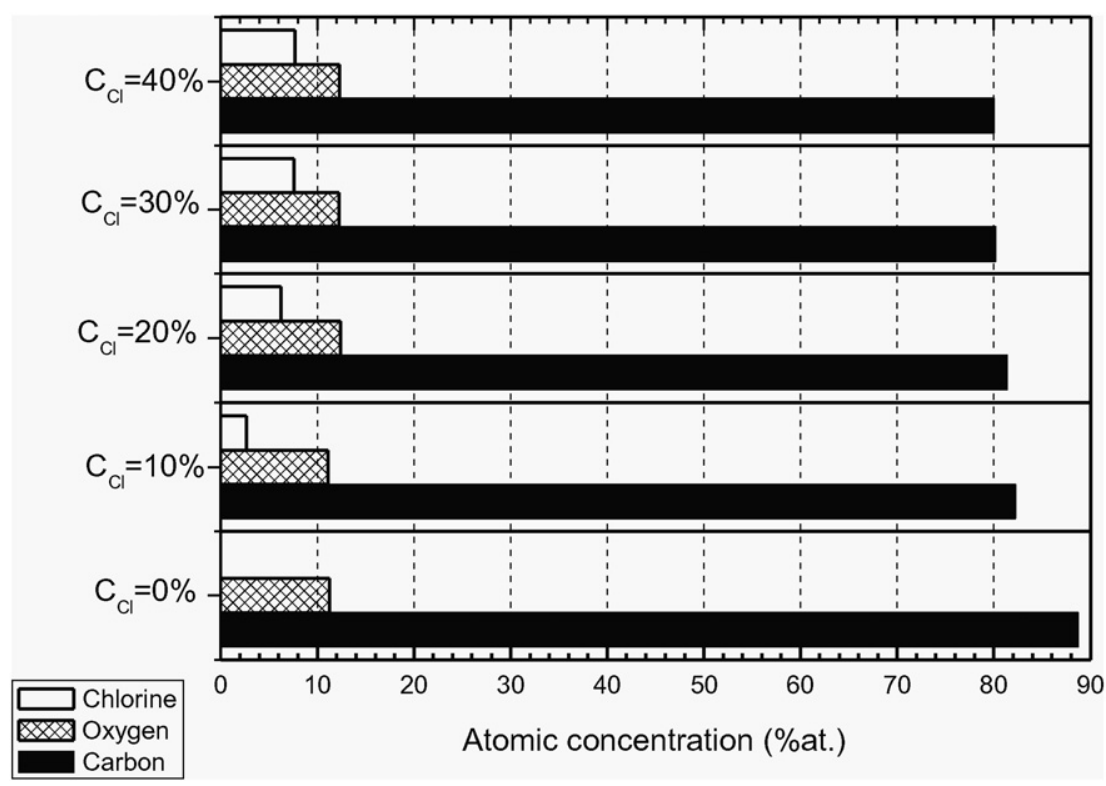

Fig. 5. Elemental composition, determined by XPS, of the films deposited at different $C_{\mathrm{Cl}}$.

\subsection{Optical properties}

Fig. 6 shows the transmittance ultraviolet-visible-near infrared spectra in the 200 to $2000 \mathrm{~nm}$ wavelength range. For clarity the spectra are offset in the vertical direction. Well-defined interference extrema are clearly observed.

Using the spectra of Fig. 6 and the film thicknesses (given in the legend of Fig. 1a), refractive indices and absorption coefficients were calculated. Fig. 7 shows the absorption coefficient of each film as a function of the photon energy.

The refractive index of the films was in the 1.54 to 1.58 range independently of $\mathrm{C}_{\mathrm{Cl}}$. We have not found independent measurements of the refractive index of plasma polymerized propanol. Films deposited in plasmas fed acetylene [25] or methanol [26], however, have refractive indices of about 1.75 and 1.69 , respectively. These are higher than that of the film deposited from propanol without chloroform in the feed, namely $\sim 1.56$. The difference is attributed to the similar but not identical monomers, the different reactor geometries, applied powers and plasmogenic gases employed. The refractive indices of the chlorinated films, however, are consistent with that determined for a film deposited from an acetylene-chloroform mixture, namely $1.59 \pm 0.04$ [15].

Taking the refractive index, $\mathrm{n}$, of the films to be governed by the Clausius-Mossotti equation, $\mathrm{n}$ depends on the density, molecular weight and polarization characteristics [27], it can be inferred from the roughly constant values of $n$ either that these factors vary in a compensating fashion or that they show little variation.

An increase in the density of $\mathrm{C}-\mathrm{Cl}$ bonds at the expense of $\mathrm{C}-\mathrm{H}$ bonds tends to increase the refractive index of conventional polymers since the former have more polarizable bonds $[28,29]$. A similar mechanism might occur in amorphous films. In the present study, however,

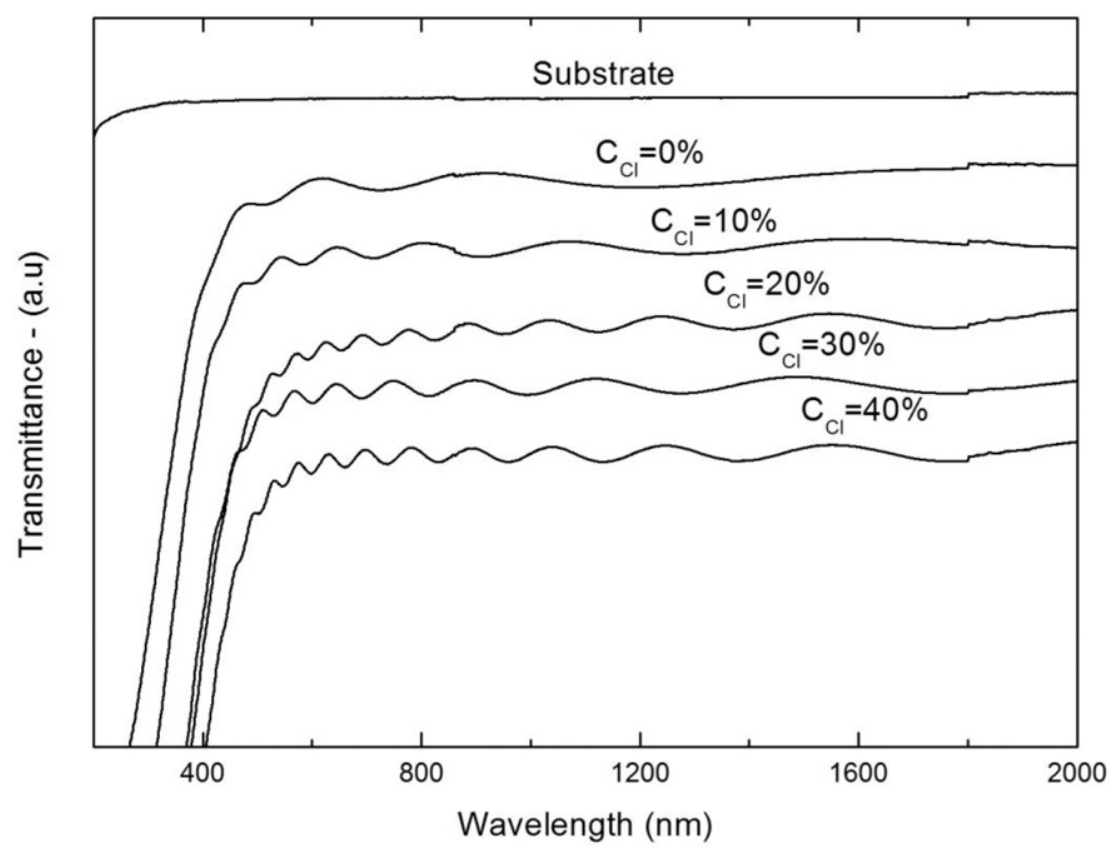

Fig. 6. Transmission ultraviolet-visible near-infrared spectra of films deposited at different $\mathrm{C}_{\mathrm{Cl}}$. To aid visualization, the spectra have been offset in the vertical direction. 


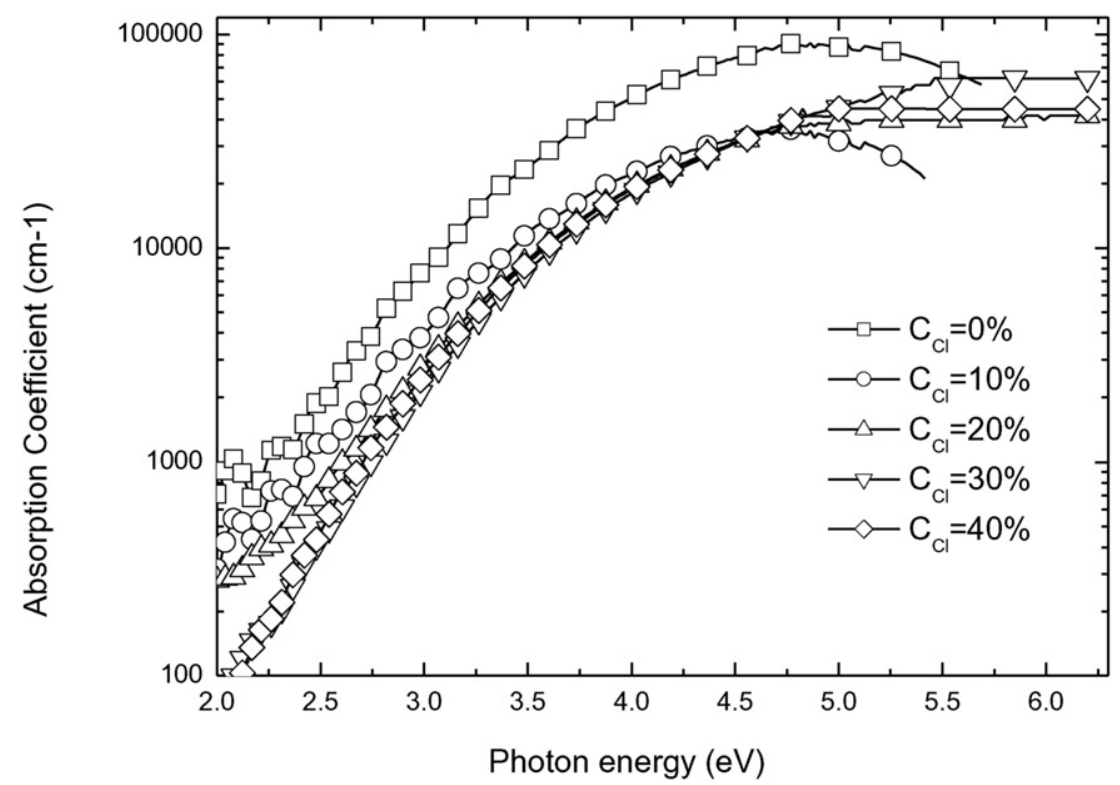

Fig. 7. Absorption coefficients as a function of the photon energy of films deposited at different $\mathrm{C}_{\mathrm{Cl}}$.

significant densities of $\mathrm{C}-\mathrm{Cl}$ were not detected in the infrared spectra but XPS analyses show $\mathrm{Cl}$ to be present at a few at.\%. Even though $\mathrm{C}-$ $\mathrm{Cl}$ groups are likely present in the films, and the film $\mathrm{C}$ content decreases with increasing $\mathrm{C}_{\mathrm{Cl}}$, the relative density of $\mathrm{CH}$ groups is greater for $\mathrm{C}_{\mathrm{Cl}}>0 \%$ (Fig. 4), thus overall $\mathrm{C}-\mathrm{Cl}$ bonds are not produced at the expense of $\mathrm{C}-\mathrm{H}$ bonds.

Fig. 8 shows the Tauc gaps [24] (calculated form Tauc plots, not shown). The chlorinated films all show $\mathrm{E}_{\text {Tauc }}$ values of $\sim 2.5 \mathrm{eV}$, which are well above that of the unchlorinated film $(\sim 1.9 \mathrm{eV})$. Although the maximum $\mathrm{Cl}: \mathrm{C}$ ratio is only $0.1, \mathrm{C}-\mathrm{Cl}$ bonds have lengths of $176 \mathrm{pm}$ compared to $\sim 106 \mathrm{pm}$ for $\mathrm{C}-\mathrm{H}$ bonds [30]. Thus the presence of $\mathrm{C}-\mathrm{Cl}$ bonds may decrease optical absorption and thus increase the gap. Inspection of the curves of Fig. 7 confirms that there is usually a decrease in absorption at any given photon energy as $\mathrm{C}_{\mathrm{Cl}}$ is increased. A similar factor influencing the gap is the tendency to greater densities of $\mathrm{C}-\mathrm{OH}$ at the expense of $\mathrm{C}=\mathrm{O}$ bonds as $\mathrm{C}_{\mathrm{Cl}}$ increases, which may also modify absorption since the respective bond lengths are about 121 and $132 \mathrm{pm}$ [30]. We also note in closing that polymeric a-C:H films have optical gaps of $\sim 3 \mathrm{eV}$ [31], which is similar to those presented by the chlorinated films of the present study.

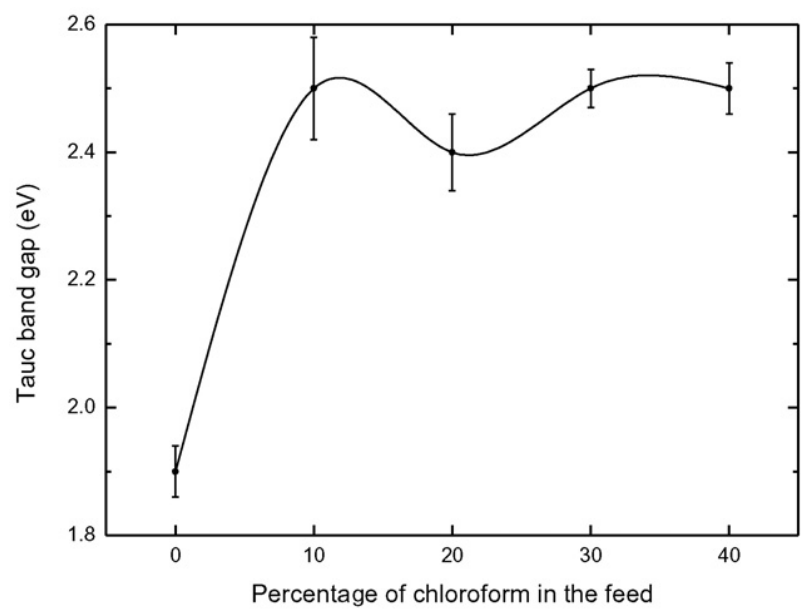

Fig. 8. The Tauc gap of the films as a function of $\mathrm{C}_{\mathrm{Cl}}$. The spline is an eye-guide only.

\section{Conclusions}

Amorphous chlorinated polymers (a-C:H:O:Cl) may be readily produced from cold plasmas fed mixtures of propanol, chloroform and argon in a simple RF plasma deposition system evacuated using a rotary pump. Relatively high deposition rates of about $110 \mathrm{~nm} \mathrm{~min}^{-1}$ can be achieved. There are few extant studies of such material. Propanol is a cheap and widely available monomer. The chlorine content hardly increases as the percentage of chloroform in the feed is raised beyond $\sim 20 \%$. A maximum $\mathrm{Cl}$ content of $\sim 8$ at.\% is reached.

The refractive index of the films remains at about 1.56 independently of the chlorine content. In contrast, the chlorinated films show a marked increase in their optical gap from roughly $1.9 \mathrm{eV}$ to $2.5 \mathrm{eV}$, suggesting possible application in optoelectronics.

An alternative application, not investigated here, is to use the chlorinated films as intermediate states for the attachment of other chemical groups to the treated surface. There is the possibility that a selected chemical group can displace chlorine at the film surface. This possibility is suggested by the presence of hydroxyl groups in the chlorinated films as shown by the infrared spectra (Fig. 3).

\section{Acknowledgments}

We thank the Brazilian agencies FAPESP (2014/21594-9) and CNPq (301622/2012-4) for financial support.

\section{References}

[1] N. Inagaki, S. Tasaka, M. Imai, Hydrophlic surface modification of polypropylene films by $\mathrm{CCl}_{4}$ plasma, J. Appl. Polym. Sci. 48 (1993) 1963-1972.

[2] N. Inagaki, S. Tasaka, Y. Suzuki, Surface chlorination of polypropylene film by $\mathrm{CHCl}_{3}$ plasma, J. Appl. Polym. Sci. 51 (1994) 2131-2137.

[3] D.J. Upadhyay, N.V. Bhat, Surface modification and characterization of dichloromethane plasma treated polypropylene film, Plasmas Polym. 8 (4) (2003) 237-257.

[4] J. Tyczkowski, I. Krawczyk, B. Wozniak, Modification of styrene-butadiene rubber surfaces by plasma chlorination, Surf. Coat. Technol. 174-175 (2003) 849-853.

[5] W. Lu, T. Cao, Q. Wang, Y. Cheng, Plasma-assisted synthesis of chlorinated polyvinyl chloride (CPVC) using a gas-solid contacting process, Plasma Process. Polym. 8 (2011) 94-99.

[6] X.A. Cao, Y.Q. Zhang, Performance enhancement of organic light-emitting diodes by chlorine plasma treatment of indium tin oxide, Appl. Phys. Lett. 100 (18) (2012) 183304, http://dx.doi.org/10.1063/1.4709426.

[7] J. Hubert, C. Poleunis, A. Delcorte, P. Laha, J. Bossert, S. Lambeets, A. Ozkan, P. Bertrand, $\mathrm{H}$. Terryn, F. Reniers, Plasma polymerization of $\mathrm{C}_{4} \mathrm{Cl}_{6}$ and $\mathrm{C}_{2} \mathrm{H}_{2} \mathrm{Cl}_{4}$ at atmospheric pressure, Polymer 54 (2013) 4085-4092. 
[8] C. Vandenabeele, R. Maurau, S. Bulou, F. Siffer, M. Gérard, T. Belmonte, P. Choquet, Continuous deposition of organo-chlorinated thin films by atmospheric pressure dielectric barrier discharge in a wire-cylinder configuration, Plasma Process. Polym. 11 (2014) 1089-1101.

[9] J.C. Alonso, R. Vasquez, A. Ortiz, V. Pankov, E. Andrade, Effect of hydrogen dilution on the remote plasma enhanced chemical vapor deposition of chlorinated $\mathrm{SiO}_{2}$ films, J. Vac. Sci. Technol. A 16 (6) (1998) 3211-3217.

[10] T. Arai, T. Nakamura, H. Shirai, Fast deposition of amorphous and macrocrystalline silicon films from $\mathrm{SiH}_{2} \mathrm{Cl}_{2}-\mathrm{SiH}_{4}-\mathrm{H}_{2}$ by plasma-enhanced chemical vapor deposition Japanese, J. Appl. Phys. 36 (1997) 4907-4910.

[11] M. Vásquez, G.J. Cruz, M.G. Olayo, T. Timoshina, J. Morales, R. Olayo, Chlorine dopants in plasma synthesized heteroaromatic polymers, Polymer 47 (2006) 7864-7870.

[12] T.D. Michl, B.R. Coad, M. Doran, A. Hüsler, J.D.P. Valentin, K. Vasiliev, H.J. Griesser, Plasma polymerization of 1,1,1-trichloroethane yields a coating with robust antibacterial surface properties, RSC Adv. 4 (2014) 27604-27606.

[13] C.J. Jahagirdar, L.B. Tiwari, Study of plasma polymerization of dichloromethane on cotton and polyester fabrics, J. Appl. Polym. Sci. 94 (2004) 2014-2021.

[14] R. Turri, C.U. Davanzo, W. Schreiner, J.H. Dias da Silva, M.B. Appolinario, S.F. Durrant, Structural and optical properties of chlorinated plasma polymers, Thin Solid Films 52 (2011) 1442-1445.

[15] R.G. Turri, R.M. Santos, E.C. Rangel, N.C. da Cruz, J.R.R. Bortoleto, J.H. Dias da Silva, C.A. Antonio, S.F. Durrant, Optical, mechanical and surface properties of amorphous carbonaceous thin films obtained by plasma enhanced chemical vapor deposition and plasma immersion ion implantation and deposition, Appl. Surf. Sci. 280 (2013) 474-481.

[16] R.M. Santos, R. Turri, E.C. Rangel, N.C. da Cruz, W. Schreiner, C.U. Davanzo, S.F. Durrant, Diverse amorphous carbonaceous thin films obtained by plasma enhanced chemical vapor deposition and plasma immersion ion implantation and deposition, Phys. Procedia 32 (2012) 48-57.

[17] E.C. Rangel, S.F. Durrant, R.C.C. Rangel, M.E. Kayama, R. Landers, N.C. da Cruz, Amorphous carbon nitrogenated films prepared by plasma immersion ion implantation and deposition, Thin Solid Films 515 (2006) 1561-1567.

[18] J. Laimer, G. Misslinger, H. Störi, Diamond deposition with chlorinated methanes: investigation of the plasma chemistry, Surf. Coat. Technol. 174-175 (2003) 938-942.
[19] S.M.D. Prestes, S.D. Mancini, E.C. Rangel, N.C. da Cruz, W.H. Schreiner, A.R. Junior, Plasma treatment to improve the surface properties of recycled post-consumer PVC, Plasma Process. Polym. 12 (2015) 456-465.

[20] S. Guruvenket, G.M. Rao, M. Komath, A.M. Raichur, Plasma surface modification of polystyrene and polyethylene, Appl. Surf. Sci. 236 (1) (2004) 278-284

[21] W.A. Lanford, M.J. Rand, The hydrogen content of plasma-deposited silicon nitride, J. Appl. Phys. 49 (4) (1978) 2473-2477.

[22] N. Morosoff, B. Crist, M. Bumgarner, T. Hsu, H. Yasuda, Free radicals resulting from plasma polymerization and plasma treatment, J. Macromol. Sci. Chem. A 10 (3) (1976) 451-471.

[23] H. Yasuda, M.O. Bumgarner, H.C. Marsh, N. Morosoff, Plasma polymerization of some organic compounds and properties of the polymers, J. Polym. Sci. Polym. Chem. Ed. 14 (1976) 195-224.

[24] J. Tauc, in: F. Abeles (Ed.), Optical properties of solids, North-Holland, Amsterdam, 1972 (Ch. 5).

[25] S.F. Durrant, R.P. Mota, M.A. Bica de Moraes, Relationships between the plasma environment and the composition and optical properties of plasma-polymerized thin films produced in rf discharges of $\mathrm{C}_{2} \mathrm{H}_{2}-\mathrm{SF}_{6}$ mixtures, J. Appl. Phys. 71 (1) (1992) 448-455.

[26] S.F. Durrant, E.C. Rangel, N.C. da Cruz, N. Marçal, P.R. Pedroso, M.A. Bica de Moraes, I. Hernndez-Caldron, Nitrogenated amorphous carbon films deposited from plasmas of methanol-nitrogen mixtures, surfaces, vacuum, and their applications, in: R. Asomoza (Ed.), AIP Conf. proc. 378, AIP Press, Woodbury, New York 1996, pp. 283-286.

[27] R.P. Feynman, R.B. Leighton, M. Sands, The Feynman Lectures on Physics, vol. II, Addison-Wesley Publishing Co., Reading, MA, 1964 32-37.

[28] K. Han, K. You, Jang W-H, T.H. Rhee, Synthesis and properties of chlorinated polyimide, Macromol. Chem. Phys. 201 (6) (2000) 747-751.

[29] D.W. van Krevelen, Properties of Polymers, Elsevier, Amsterdam, 1976.

[30] Handbook of Chemistry and Physics, 65th edition, CRC Press, Weast, Robert C. (editor-in-chief) (1984).

[31] S. Neuville, New Application Perspective for Tetrahedral Amorphous Carbon Coatings, QScience Connect, 82014 (http://dx.doi.org/10.5339/connect.2014.8). 